$\begin{array}{cccc}\text { Revista do Departamento de Geografia USP } & \begin{array}{c}\text { Revista do Departamento de Geografia } \\ \text { Universidade de São Paulo } \\ \text { www.revistas.usp.br/rdg }\end{array} \\ \text { ISSN 2236-2878 } & \text { V.31 (2016) }\end{array}$

\title{
A ESTRATÉGIA DE INTEGRAÇÃO DO SUL DO ESTADO DE MATO GROSSO AO TERRITÓRIO NACIONAL DURANTE O GOVERNO VARGAS:UMA ANÁLISE A PARTIR DA CRIAÇÃO DA COLÔNIA AGRÍCOLA NACIONAL DE DOURADOS EM 1943
}

\section{THE STRATEGY OF INTEGRATION OF THE SOUTH OF THE STATE OF MATO GROSSO TO THE NATIONAL TERRITORY DURING THE GOVERNMENT OF PRESIDENT VARGAS: AN ANALYSIS FROM THE FOUNDATION OF NATIONAL AGRICULTURAL COLONY OF DOURADOS IN 1943}

\author{
Walter Guedes Silva \\ Universidade Estadual de Mato Grosso do Sul \\ guedes@uems.br
}

Recebido (Received): 26/08/2015 Aceito (Accepted): 26/12/2015 DOI: http://dx.doi.org/10.11606/rdg.v31i0.102834

\begin{abstract}
Resumo: O apelo ao nacionalismo marcou o discurso do Presidente da República do Brasil Getúlio Vargas (19301945), que se utilizou da mídia para convocar os trabalhadores à conquista do território nacional, que se daria por meio da política migratória e colonizadora condizente com a necessidade de integração territorial e de industrialização do país. Para isso, Vargas criou oito Colônias Agrícolas Nacionais, dentre elas, a Colônia Agrícola Nacional de Dourados no Sul do estado do Mato Grosso, hoje estado do Mato Grosso do Sul. O objetivo deste artigo consiste em analisar a criação da Colônia Agrícola Nacional de Dourados, em 1943, como forma de garantir a integridade da fronteira entre BrasilParaguai e a integração da região atendida por esse projeto colonizador ao território nacional. Os procedimentos adotados repousaram na revisão da bibliografia regional e em discursos do então presidente Getúlio Vargas, que contribuiu para a compreensão dos ideais do governo Vargas em implantar uma política que (re)estruturou o território regional em pequenas propriedades familiares, como forma de garantir a integração dessa região ao mercado nacional como produtora de matéria-prima e receptora de correntes migratórias.
\end{abstract}

Palavras-chave: colonização; pequena propriedade; integração regional.

\begin{abstract}
The call for nationalism marked the speech of the Brazilian Republican President Getúlio Vargas (1930-1945), who used the media to convene workers to conquer the national territory, through the colonizing and migration policy in accordance with the need for territorial integration and the country's industrialization. Therefore, Vargas created eight National Agricultural Colonies, among them, the National Agricultural Colony of Dourados in the south of Mato Grosso, which has become the state of Mato Grosso do Sul. The aim of this article is to analyze the foundation of the Colonia Agrícola Nacional (National Agricultural Colony) of Dourados in 1943, as a way to guarantee the integrity of the border between Brazil and Paraguay and the integration of the area covered by this colonizing project to the national territory. The used procedure was the historical review which revealed the ideals of Vargas's presidency in order to establish policies that (re)structured the regional territory into small family farms, assuring the integration of this area to the national market as a producer of raw material and recipient of migratory flows.
\end{abstract}

Keywords: colonization; small land property; regional integration. 


\section{INTRODUÇÃO}

Para superar a crise de 1929, o governo brasileiro, sob a figura do então presidente Getúlio Vargas, idealizou, no período de 1930 a 1945, uma política de investimentos no setor industrial e na produção agrícola, sendo esta a base da economia nacional. Para isso, adotou algumas medidas para incentivar a indústria nacional e conduzir a produção agrária aos interesses industriais, com a ocupação do território brasileiro que combinasse colonização e industrialização.

Criadas no governo de Getúlio Vargas, as Colônias Agrícolas Nacionais (CANs) possibilitaram a ocupação das regiões atingidas por esse projeto de colonização caracterizado pela reestruturação do território em pequenas propriedades rurais ${ }^{1}$, consolidando uma produção agrícola voltada para o abastecimento do mercado regional. Das oito colônias agrícolas criadas pelo governo Vargas $^{2}$, este texto analisa a única colônia que teve como objetivo garantir a integridade da fronteira entre Brasil e Paraguai, e a integração da região de Dourados, localizada no sul do estado do Mato Grosso do Sul, à economia nacional, denominada Colônia Agrícola Nacional de Dourados (CAND).

\section{A integração do mercado interno brasileiro}

No início do século 20, as principais atividades econômicas do país eram mais vinculadas com o mercado externo do que com o mercado interno, configurando um território nacional pouco integrado internamente e constituído por complexos regionais exportadores. Mas a crise de 1929 rompeu as formas de acumulação assentada na economia agroexportadora a favor de um crescimento endógeno e de um mercado interno integrado, orientado para o crescimento industrial.

Em discurso proferido na cidade de Goiânia (GO) em agosto de 1940, o presidente Getúlio Vargas deixou explícito seu ideal de integrar o território nacional e de superar a dicotomia do território que se encontrava dividido em duas partes distintas: uma, que produzia e exportava; e a outra, que comprava e vendia matéria-prima. Assim, "cabia, através do imperialismo interno, fazer com que as ilhas de prosperidade industrial ocupassem os espaços despovoados, desfizessem o arquipélago e rearticulassem o país continental" (VARGAS, 1941, p. 31).

A concepção de nacionalismo perpassava a ideia de que a fronteira econômica do país deveria avançar e coincidir com o limite internacional entre os países. Segundo Machado (2010, pp. 60-61), "o limite internacional foi estabelecido como conceito jurídico associado ao Estado territorial no sentido de delimitar espaços mutuamente excludentes e definir o perímetro máximo de controle soberano exercido por um Estado central. " Diferente é o conceito de fronteira que "[...] se faz pela territorialização de grupos humanos e de redes de circulação e intercâmbio [...]." (MACHADO, 2010, p. 62).

A ideia de fronteira econômica adotada por Vargas estava relacionada às atividades econômicas existentes no território nacional, quanto mais atividades econômicas próximas do limite internacional, mais próspera e forte seria a nação. Uma proximidade que se daria pela integração das regiões de baixa densidade demográfica ao circuito produtivo nacional, pela reorganização das relações sociais das diferentes regiões do país e pela formação de um mercado de produção e de consumo.

\footnotetext{
${ }^{1}$ As propriedades rurais podem ser definidas em: minifúndio, com tamanho de até um módulo fiscal; pequena propriedade, entre um e quatro módulos fiscais; média propriedade, com tamanho acima de quatro e até quinze módulos fiscais; e, grande propriedade, acima de 15 módulos fiscais. No município de Dourados o módulo fiscal corresponde a 30 ha. (BRASIL, 2013).

${ }^{2}$ Por meio do Decreto 3.509, de 14 de fevereiro de 1941, governo Vargas criou 8 Colônias Agrícolas Nacionais: Colônia Agrícola Nacional de Goiás (Decreto 6.882, de 19/02/1941); Colônia Agrícola Nacional do Amazonas (Decreto 8.506, de 30/12/1941); Colônia Agrícola Nacional do Maranhão (Decreto 10.325, de 27/08/1942); Colônia Agrícola Nacional do Pará (Decreto 5.240, de 10/02/1943); Colônia Agrícola Nacional "General Osório" no Paraná (Decreto 12.417, de 12/05/1943); Colônia Agrícola Nacional de Dourados (Decreto 5.941, de 28/10/1943); Colônia Agrícola Nacional do Piauí (Decreto 16.780, de 10/10/1944) e Colônia Agrícola Nacional de Jaíba (Decreto 25.547, de 21/09/1948). (FREITAS; MELLO, 2014, p. 474).
} 
“O imperialismo brasileiro consiste, portanto, na expansão demográfica e econômica dentro do próprio território, fazendo a conquista de si mesmo e a integração do Estado, tornando-o de dimensões tão vastas quanto o país" (VARGAS, apud COSTA, 2007, p. 93). O referido imperialismo encontrou apoio em parcelas da sociedade que viram nas ações interventoras do Estado e na reestruturação do aparelho estatal, uma expectativa de superação da crise e de emergência econômica da sociedade. As ações centralizadoras do governo Vargas foram conduzidas para atender algumas premissas, como: integração do mercado (o que exigia um reordenamento populacional e a criação de infraestrutura básica de produção e transporte), desenvolvimento da indústria de bens de produção e de consumo,

Para Oliveira (1999, pp. 39-40), as estratégias utilizadas pelo governo Vargas não se resumiam em solucionar os problemas das cidades; eram antes um projeto político que visava desenvolver o capitalismo no Brasil, "projeto este que, na prática, atendia muito mais à classe industrial ascendente do que aos trabalhadores que, nos discursos de Vargas, eram tratados como o centro das atenções". Na visão da autora, o real interesse do governo era o de reordenar o capitalismo no país. Tal afirmativa se sustenta no próprio discurso de Vargas proferido no dia 1 de maio de 1941:

É necessário à riqueza pública que o nível de prosperidade da população rural aumente para absorver a crescente produção industrial; é imprescindível elevar a capacidade aquisitiva de todos os brasileiros - o que só pode ser feito aumentando-se o rendimento do trabalho agrícola. (VARGAS, 1941, p. 261).

A expansão da fronteira econômica do país e a formação de um mercado nacional estavam articuladas com a necessidade do capital: a industrialização. Aumentar a indústria do consumo atendia aos interesses do Estado e da iniciativa privada, pois se aumentava a acumulação de capital fundamental para a unificação do mercado nacional. O desenvolvimento econômico brasileiro, que se processou após a crise de 1929, entrou numa nova fase, não mais pautado pelas atividades agroexportadoras, mas pela indústria e pela integração do mercado interno.

É quando o Sudeste brasileiro, em especial o estado de São Paulo, assumiu, a partir de 1930, o papel de centro hegemônico do capital industrial, interferindo na função das demais regiões do território nacional num processo de complementaridade inter-regional condizente com a lógica de reprodução do capital.

\section{O estado de São Paulo como centro de acumulação do capital industrial}

A baixa integração entre as diversas regiões do Brasil, com precárias condições de transporte e de comunicação; a escassa dinâmica regional; a concentração fundiária e de investimentos no Sudeste brasileiro e a rigidez tecnológica, fizeram com que, pelo menos até a crise de 1929, as economias regionais existissem sem grandes ameaças de competição, o que contribuiu, na visão de Cano e Guimarães Neto (1986, p. 177), para a formação de verdadeiras "ilhas" econômicas no território nacional, com baixa integração inter-regional e com a formação de uma estrutura produtiva hierarquizada, preocupada, principalmente, com o mercado externo.

Com o aumento da concentração industrial e com uma agricultura mais diversificada, o estado de São Paulo se destacou das demais regiões do Brasil no final do século 19 e início do século 20. A Primeira Guerra Mundial (1914-1918) provocou crise no comércio exterior, diminuindo tanto a exportação como a importação nacional, fase em que São Paulo se despontou no cenário nacional como o estado que obtinha as melhores condições de abastecimento do mercado interno. 
O lucro que o estado de São Paulo obteve no período de crise, conferindo-lhe aumento real na acumulação industrial, proporcionou vantagens competitivas para uma integração inter-regional no período de recuperação econômica e de extensa abertura do comércio exterior na década de 20. Segundo Cano e Guimarães Neto (1986, p. 178), no período de 1900-1910, 15\% das exportações totais do estado de São Paulo foram direcionadas para os demais estados brasileiros e $85 \%$ para outros países; em 1960 essa porcentagem foi invertida, passando para 84\% e 16\% respectivamente, evidenciando um quadro econômico em que o estado de São Paulo assume, cada vez mais, o papel de centro econômico do país.

As mudanças que se processaram a partir de 1929 não provocaram apenas o deslocamento do eixo de acumulação do setor agroexportador para o industrial, pois a limitação às importações, ocorrida pela desarticulação do comércio externo, obrigou o aumento da complementaridade interregional. "Passava-se, portanto, a integrar o mercado nacional sob o predomínio de São Paulo. À periferia nada mais restava do que se ajustar a uma função complementar da economia de São Paulo." (CANO e GUIMARÃES NETO, 1986, p. 61).

Nessa fase, as regiões próximas a São Paulo, Mato Grosso, Minas Gerais e Paraná, estavam mais predispostas a receberem os impactos positivos da integração, seriam as regiões de avanço da fronteira agrícola, que nada mais é do que a expansão da unidade de produção capitalista no campo.

\section{A nacionalidade verde-amarela e a integração nacional}

Após os anos 30 de século 20, o Brasil passa por uma relativa dependência do setor agroexportador para determinar a capacidade de importação do mercado nacional e com uma restrita produção de bens de produção.

A manutenção da demanda, juntamente com o corte das importações, revela para a indústria nacional a incumbência de abastecer o mercado interno, que mais tarde, expandirá sua produção para setores como da agricultura e do urbano. Mas só o potencial industrial de São Paulo com capacidade de produção ociosa, não lhe garantia, por si só, o posto de centro dinâmico da economia capitalista, fazia-se necessário uma integração nacional após a crise de 1929, no dizer de Goldenstein e Seabra (1982, p. 30), esse período "corresponde à formação do mercado nacional e, portanto, ao processo de unificação econômica do espaço brasileiro e de sua efetiva regionalização interna."

A expansão da fronteira agrícola para o Centro-Oeste, permitiu que esta região se configurasse como "extensão da agricultura do Sudeste. " (GOLDENSTEIN e SEABRA, 1982, p. 32). Assim, o Centro-Oeste aproveitou os efeitos de estímulos do Sudeste, em especial de São Paulo, para especializar-se na produção de matéria-prima dentro de uma lógica de produção voltada a atender ao mercado nacional e internacional, buscando para isto, uma inserção ao Padrão Agrário Moderno de Produzir.

Segundo Goldeinstein e Seabra (1982, p. 39), o “caráter de extensão do Sudeste é dado também pela própria forma de valorização do capital, favorecidas pela atuação do Estado na expansão das atividades agrárias." Ainda segundo os autores, tal expansão seria dada "pela penetração de grandes lavouras industriais como soja-trigo [...], pelo avanço renovado da pecuária [...] e pelo extravasamento das áreas de invernadas de São Paulo e do Triângulo Mineiro para o sul de Goiás e sudeste de Mato Grosso do Sul." A expansão da fronteira agrícola e a integração territorial são formas de valorização do capital.

Para que a integração nacional se efetivasse, o governo federal adotou algumas medidas de estímulo ao deslocamento populacional como ação indispensável para a integração de mercado. Esse deslocamento forneceu a mão de obra trabalhadora e os consumidores necessários para o avanço da indústria, formando não só um mercado de consumo, mas aquilo que Costa (2007, p. 33) chama de "mercado nacional de trabalho, qualitativamente diferente, associado às novas exigências do desenvolvimento industrial". 
A integração do mercado nacional, sustentada por uma política de industrialização, levou o governo a adotar medidas protecionistas por meio de tarifas e tributos, uma alternativa para que os produtos nacionais concorressem com os produtos estrangeiros. Para articular a integração do mercado nacional, o governo também eliminou impostos e taxas interestaduais e investiu na melhoria dos meios de transportes.

A incorporação de novas regiões ao circuito produtivo nacional, que se efetivou pela política colonizadora orientada para a formação de um mercado nacional integrado aos centros dinâmicos da economia nacional, trouxe à tona os discursos em torno da integridade nacional.

A ampliação do mercado, por sua vez, implicava a necessidade de se transformar as frentes de expansão em regiões produtoras e consumidoras de mercadorias, anexando-as ao desenvolvimento capitalista e, ao mesmo tempo, de se coordenar esses movimentos de maneira que permitissem a conquista de novas áreas, incorporando-as definitivamente ao mercado nacional. O tamanho do mercado interno nacional, por isso, indicava a preocupação com a integridade do território e, consequentemente, com a defesa e a segurança nacional. Tais elementos impuseram às políticas colonizadoras uma importância fundamental. (COSTA, 2007, p. 57).

A integração do mercado interno brasileiro, amparado pela redistribuição da população no território nacional, era indispensável para o crescimento do modelo capitalista sustentado pela indústria de bens de consumo, o que garantiria a formação de um mercado de produção e de consumo, com oferta de matéria-prima para a indústria e de alimentos para os centros urbanos, além da formação de núcleos consumidores dos produtos industriais produzidos no próprio país, principalmente no estado de São Paulo.

Para minimizar os problemas do desemprego dos centros urbanos, o governo Vargas incentivou a migração da população localizada nas regiões consideradas críticas, como o Nordeste, para os chamados vazios demográficos, que nada tinham de vazio, que deveriam ser ocupados, como o Centro-Oeste. Embora houvesse uma desarticulação econômica do território CentroOestino, nessa região havia, além dos índios, trabalhadores de garimpos, fazendas e moradores das cidades e vilas.

O incentivo à migração era uma alternativa que atenuaria os conflitos gerados pela pressão populacional existente nas cidades, geraria empregos, ocuparia as áreas de fronteira por brasileiros, dinamizaria a produção agrícola e formaria um mercado de consumo dos produtos industriais.

O retorno dos desempregados da cidade para o campo, fruto do êxodo rural, era uma das propostas de Vargas (1940, p. 115): "O proletariado das cidades aumentou desproporcionadamente [...]. Cumpre-nos incentivar, por todas as formas, a volta ao bom caminho. Os atalhos que nos podem levar a ele são muitos, mas o rumo, um só: o retorno aos campos".

A retirada dos migrantes do campo, que estavam nas cidades, era fundamental para o estabelecimento da ordem desejada pelo governo, esvaziando as tensões sociais das cidades superlotadas de desempregados oriundos da zona rural. A política migratória tornou-se parte integrante das estratégias do governo para reordenar o capitalismo no país, que também se defrontava com o crescimento dos imigrantes estrangeiros, aumentando a pressão por empregos nas cidades.

Em 1931, o governo federal estipulou que pelo menos 2/3 dos empregos do país fossem destinados aos trabalhadores brasileiros. A crítica à imigração de estrangeiros, que até pouco tempo era vista como aspecto positivo para a economia nacional, repousava na necessidade de construir a nacionalidade brasileira, sem a qual não se garantiria a integração nacional. É importante destacar que a nacionalidade do governo Vargas não se repousava na presença de qualquer brasileiro em 
regiões de fronteira; índios e descendentes de negros não faziam parte desse quadro; a nacionalidade verde-amarelo foi orientada para o capital e não para o homem. A respeito dos brasileiros que deveriam povoar as regiões colonizadas, Vargas (1938, p. 28) relata:

\begin{abstract}
É preciso agrupá-los, instituindo colônias agrícolas [...]; incutindo-lhes hábitos de atividade e economia. Tal é a valorização básica, essa sim, que nos cumpre iniciar quanto antes a valorização do capital humano, por isso que a medida da utilidade social do homem é dada pela sua capacidade de produção (grifo meu).
\end{abstract}

De acordo com Costa (2007, p. 86), o governo Vargas adotou medidas consideradas fundamentais para "a correta expressão do nacionalismo e a construção da nacionalidade brasileira", as quais eram superar o atraso e o abandono do trabalhador do campo e das grandes propriedades rurais improdutivas ou subaproveitadas e padronizar as relações sociais de produção e as características culturais como língua e costumes.

Ao redistribuir a população dos grandes centros para expandir a fronteira econômica do país, o Estado assumiu o papel de construtor do novo trabalhador nacional que, apoiado em discursos nacionalistas propagados pela mídia e por uma legislação trabalhista, imprimiu uma forte ideologia populista pautados na ocupação do dito vazio demográfico e na ocupação das áreas vocacionadas à agropecuária. Referindo-se a visão do governo Vargas em relação do Centro-Oeste, Abreu (2003, p. 263), afirma que "é essa a concepção (e a função) que lhes foi atribuída no interior da divisão territorial do trabalho até início dos anos de 1970."

O incentivo à migração desarticulou os movimentos oposicionistas ao governo, consolidou a ocupação da região de fronteira e inseriu dezenas de milhares de trabalhadores ao circuito produtivo nacional. Tal inserção deu-se com forte atuação do Estado que criou, em 1933, o Departamento Nacional de Trabalho (DNT) e, em 1938, o Conselho de Colonização e Imigração (CIC), que tiveram o objetivo de reordenar os trabalhadores e estabelecer uma política de ocupação do território.

Ao redistribuir a população desempregada do país, o DNT garantiu o controle sobre parte dos trabalhadores e a reprodução do capital, assentada na pequena propriedade rural. Durante o primeiro governo Vargas (1930-1945) foram criados mais de 30 órgãos públicos (ministério, departamento, conselho, comissão, entre outros) destinados a orientar o desenvolvimento capitalista assentado na indústria nacional e na integração da economia nacional.

As regiões destinadas a receberem o fluxo migratório da política de redistribuição da população estavam inseridas num contex to político que garantiam a posse do território, a segurança da fronteira e a integração produtiva do país. O Golpe de 1937, que instituiu o Estado Novo, consolidou esse ideal do governo Vargas em reordenar a ocupação do território e reconstruir a nação, que será aqui analisado pela campanha Marcha para o Oeste.

\title{
A campanha Marcha para o Oeste e a Colônia Agrícola Nacional
}

A ideia de difundir um novo Brasil em meio às dificuldades econômicas da sociedade teve muito êxito entre os milhões de desempregados. Reconhecer e apresentar alternativas para os problemas sociais que se manifestavam de forma latente nas cidades, pautados na distribuição de terras e no apoio aos pequenos produtores familiares brasileiros, foi a alternativa do Estado Novo, que teve nas CANs o pilar de sustentação da Marcha para o Oeste.

Com discurso nacionalista e com ideais de integração nacional, o governo Vargas instituiu, em 1937, a campanha Marcha para o Oeste, desencadeando um processo de ocupação do chamado vazio demográfico, que nada tinha de vazio, como forma de desenvolvimento econômico regional e 
incentivo ao consumo dos produtos industriais. "A conquista do oeste significava para o regime a integração territorial como substrato simbólico da união de todos os brasileiros." (SKIDMORE, 2007, p. 69).

Em meio ao autoritarismo do Estado Novo surge a política desenvolvimentista, denominada "Marcha para o Oeste", que tinha como objetivo ocupar os espaços considerados vazios, povoar as regiões fronteiriças do país, e promover a integração dos estados brasileiros, sobretudo das regiões Norte e CentroOeste do país. É importante resaltar que a Marcha para o Oeste tinha por finalidade a nacionalização das fronteiras, através da expansão agrícola e da colonização do interior. Tinha- se em vista a segurança nacional e a ocupação estratégica das fronteiras. (NAGLIS, 2007, p. 27).

O apelo ao patriotismo e ao nacionalismo econômico, para a construção da nação, marcou o governo Vargas que se utilizou da mídia para convocar os trabalhadores à conquista do território nacional. Tal conquista se efetivaria por meio da política migratória e colonizadora condizente com a necessidade de integração territorial e de industrialização. Para isso, o governo criou Colônias Agrícolas e, dentre elas, a Colônia Agrícola Nacional de Dourados (CAND) no Sul do estado de Mato Grosso, hoje estado do Mato Grosso do Sul, objeto de estudo deste artigo.

$\mathrm{O}$ projeto de colonização, assentado às ideias de integridade e segurança territorial, expressava o compromisso do Estado em expandir a lógica de acumulação capitalista nacional. As ações do governo tinham, segundo Naglis (2007, p. 23), propósitos claros: "urgia unificar o mercado interno e garantir a diversificação da produção, tanto agrícola quanto industrial, cada vez mais".

Todavia, sob uma análise mais atenta, percebemos o esboço da política de colonização do Estado Novo, qual seja: desestruturar o latifúndio tradicional, apoiar a pequena propriedade produtiva, superar a velha ordem latifundiária, de modo que ela, aos poucos, instaurasse a nova realidade agrícola que o desenvolvimento industrial do País exigia, forçando, dessa maneira, a transformação agrária através de dispositivos peculiarmente orientados para tal finalidade. (OLIVEIRA, 1999, pp. 75-76).

A criação das CANs possibilitou uma ocupação regional configurada pelas pequenas propriedades rurais. Essas colônias foram pensadas no contexto de integração das regiões atingidas por esse projeto ao circuito produtivo nacional, convertendo os novos produtores oriundos de diversas partes do Brasil, em consumidores da indústria nacional. Com uma produção diversificada, os pequenos produtores foram integrados por uma dinâmica produtiva que subordinou o campo à cidade, tendo sua produção e consumo pautados pela dinâmica do urbano. As CANs foram sinônimos de expansão e integração de mercado.

\section{A criação do Território Federal de Ponta Porã e da Colônia Agrícola Nacional de Dourados (CAND)}

Antes de discutirmos a criação do Território Federal de Ponta Porã e da CAND, é importante uma contextualização do Sul do estado do Mato Grosso no final do século 19 e início do século 20, por meio da tradicional atividade econômica da erva-mate. $O$ acordo da Tríplice Aliança (Argentina, Brasil e Uruguai) realizado durante a Guerra do Paraguai (1864-1870), que definiu o limite territorial entre Brasil e Paraguai, foi decisivo para que até o final dos anos 30 do século 20, o Sul do estado do Mato Grosso se configurasse com uma estrutura produtiva caracterizada por 
grandes propriedades rurais, com exploração das atividades econômicas da erva-mate e do gado.

Segundo Silva (2011, p. 107), o fim da Guerra do Paraguai, aliado à queda da atividade mineradora centrada em Cuiabá, representou uma nova fase na reestruturação do poder político e econômico em nível regional no Mato Grosso, marcado pela perda do prestígio de Cuiabá como capital da Província e ascensão de uma nova elite na região de domínio da erva-mate.

Para Corrêa (2006, p. 52), a Guerra do Paraguai trouxe novas oportunidades de exploração dos recursos regionais ao ter possibilitado a abertura do rio Paraguai à navegação, abrindo "a brecha necessária aos investimentos de capital na região mato-grossense, tanto no setor da produção agropecuária como, principalmente, no comércio importador-exportador". A expansão das fazendas de gado na região também contou com investimento de capitais estrangeiros que adquiriram centenas de milhões de hectares para o desenvolvimento da pecuária extensiva.

A entrada de capitais estrangeiros para a criação de gado levou à formação de uma elite regional assentada na exploração da pecuária bovina. Segundo Mamigonian (1986, pp. 39-58), a presença da pecuária bovina em todo o sul do estado do Mato Grosso, caracterizada pela grande extensão territorial, não estimulou o desenvolvimento de uma malha de cidades, mas contribuiu, sobremaneira, para a atuação dos coronéis criadores de gado, que, utilizando-se muitas vezes de práticas criminosas, encontraram condições propícias para legitimar a posse da terra e o poder regional.

Segundo Corrêa (2006, pp. 18-19), a formação dos coronéis no sul do estado do Mato Grosso ocorreu no período de 1889 a 1943, quando uma elite regional se fortaleceu com a conivência de um Estado débil a serviço das oligarquias regionais. Os coronéis eram homens de poder econômico que se dedicavam a causas políticas com o uso de armas, submetendo ao seu jugo toda a sociedade regional, entre eles os índios.

Além da pecuária bovina, a outra única atividade de grande expressão econômica localizada no Sul do estado do Mato Grosso no final do século 19 e início de século 20 foi a erva-mate. Ambas impuseram uma organização regional com predomínio da grande propriedade rural, sendo as forças hegemônicas de reprodução do capital.

A exploração da erva-mate, que se inicia no sul da Província ${ }^{3}$ do Mato Grosso a partir de 1870, configurou o território regional caracterizado por três aspectos: associação do Estado ao capital empresarial para a exploração da erva-mate; monopólio de uma grande empresa na exploração da erva-mate e domínio e controle territorial que impediram/limitaram o desenvolvimento de outras atividades econômicas, a ocupação regional e a integridade de grupos tradicionais que viviam na região (SILVA, 2011, p. 112).

A ação da Cia Matte Larangeira, empresa ervateira que durante o período de 1883-1937 impôs domínio e controle territorial no Sul do estado do Mato Grosso, limitou o processo de ocupação e o desenvolvimento de outras atividades econômicas em sua área de atuação que não fossem o extrativismo da erva-mate, como atividade econômica hegemônica, e a pecuária bovina. Essa estrutura territorial não condizia com os ideais do Estado Novo em ocupar e nacionalizar a fronteira - era preciso reconfigurar o território regional.

A primeira autorização dada pelo governo da Província do Mato Grosso para explorar a ervamate, foi feita por meio do Decreto $\mathrm{n}^{\circ} .8 .779$ de 1882, na fronteira com o Paraguai. Com a proclamação da República em 1889, o general Antônio Maria Coelho, primeiro governador do estado do Mato Grosso do período republicano, prorrogou, por meio da Lei $\mathrm{n}^{\circ} .520$ de 1890, a concessão de exploração dos ervais da Cia Matte Larangeira por mais 10 anos, ampliando, sobremaneira, a área que havia sido autorizada em 1882. Em 1892, a Lei $\mathrm{n}^{\circ} .26$ amplia a área de exploração dos ervais para o extremo sul do estado do Mato Grosso. Até que em 1895, a Resolução

\footnotetext{
3 Terminologias utilizadas para se referir ao território que hoje se constitui como estado do Mato Grosso do Sul no período de 1500 até a atualidade: Adelantazgo da Província do Rio da Prata (1500 a 1617); Província do Paraguai (1617 a 1750); Capitania do Mato Grosso (1750 a 1822 ); Província do Mato Grosso (1822 a 1889); Estado do Mato Grosso (1889 a 1977); e Estado do Mato Grosso do Sul (1977 até a atualidade).
} 
$n^{\circ} .103$ destinou mais terras para a exploração da erva-mate. (SILVA, 2011).

Essas concessões (Figura 1) influenciaram, diretamente, na vida dos povos indígenas que viviam no Sul do estado do Mato Grosso, uma vez que tais concessões se deram em território Kaiuwá e Guarani. Segundo Ferreira e Falcão (2013, p. 97), os indígenas foram utilizados como mão de obra na colheita e no preparo da erva-mate. Para facilitar o controle e a exploração do Sul do território Mato-Grossense, era necessário expropriar os índios de suas terras, o que se daria por meio da criação de Reservas Indígenas - uma alternativa legal para expropriar o índio de seu território.

O estado objetivava prestar assistência e proteção aos índios, promovendo, ao mesmo tempo, a sua passagem de categoria de índios para agricultores não índios. Para isso, na visão do SPI, era fundamental a criação de reservas indígenas que permitissem liberar o restante da terra tradicionalmente ocupada pelos índios para as frentes agrícolas. (FERREIRA; FALCÃO, 2013, p. 99).

Ao todo, foram criadas, no período de 1915 a 1930, seis Reservas Indígenas no Sul do Mato Grosso, evidenciando a atuação do Estado brasileiro na consolidação do poder econômico regional representado pela Cia Matte Larangeira.

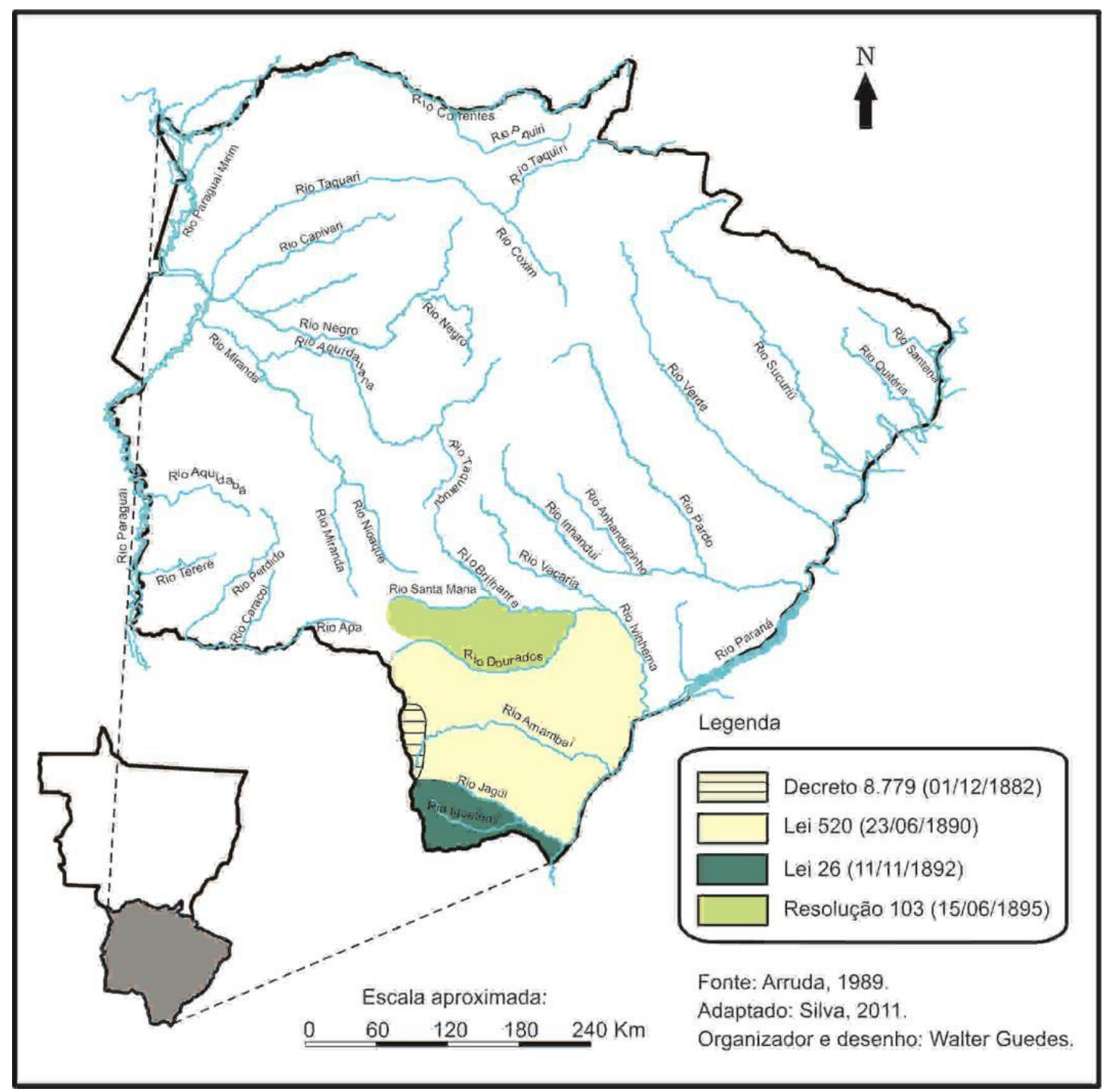

Figura 1: Área das concessões de exploração da erva-mate no Sul do estado do Mato Grosso (1882-1895) 
Para desarticular o poder da Cia Matte Larangeira, que mantinha a concessão de exploração dos ervais nativos na região, o governo agiu em terras dos ervais sob várias frentes. Em 1930, desapropriou as instalações que a Cia tinha em Guaíra, a oeste do Estado do Paraná e proibiu os serviços de navegação do alto Paraná. Em 1931, criou o Conselho Nacional do Mate (CNM), com sede no Rio de Janeiro e a cobrança da sobretaxa de 25 réis por quilo de erva-mate produzido.

Dentro do princípio de nacionalizar a fronteira e de valorizar a produção e a industrialização da erva-mate no país, o governo estimulou a produção da erva-mate no Estado do Paraná, pois nesse estado a erva era produzida em pequenas propriedades rurais e industrializada no próprio país. Tratava-se de uma realidade diferente da que ocorria no Sul do estado do Mato Grosso, onde a ervamate era produzida em grandes fazendas e exportada para os moinhos argentinos sem ser industrializada, numa relação comercial que não gerava receitas de exportação de produtos industrializados aos cofres públicos.

Antes de criar a Colônia Agrícola Nacional de Dourados, o governo Vargas precisava desarticular, definitivamente, o poder e a atuação da Cia Matte Larangeira na região, e o fez ao criar, em 1943, o Território Federal de Ponta Porã. Esse território foi criado com o desmembramento de terras do Sul do estado do Mato Grosso numa área de domínio e exploração de ervais da Cia Matte Larangeira. Com a criação do Território Federal de Ponta Porã, o direito de arrendamento para a exploração dos ervais não foi mais renovado.

Por meio do Decreto-Lei no 5.812 de 13 de setembro de 1943, o governo federal criou cinco territórios federais: Amapá, Rio Branco (atual Roraima), Iguaçu, Guaporé (atual Rondônia) e Ponta Porã. A criação do Território Federal de Ponta Porã, composto na época pelos municípios de Bela Vista, Dourados, Maracaju, Miranda, Nioaque, Ponta Porã e Porto Murtinho, coaduna perfeitamente com os interesses do Estado Novo em nacionalizar a fronteira e assumir o controle territorial em áreas de domínio do capital estrangeiro. Com a promulgação da nova Constituição Federal, em 1946, o Território Federal de Ponta Porã foi extinto e sua área foi reincorporada ao Estado de Mato Grosso. Mesmo assim, foi suficiente para tirar da Cia Matte Larangeira qualquer poder sobre as terras localizadas nesse território que ficou vinculado à União.

A criação do Território Federal de Ponta Porã (Figura 2) possibilitou não só a perda da concessão de exploração dos ervais por parte da Cia, mas também facilitou o processo de incentivo à migração e à criação da CAND, contribuindo para a desestruturação do poder da Cia Matte Larangeira.

Criada pelo Decreto Lei $\mathrm{n}^{\circ} .5 .941$ de 28 de outubro de 1943, mas instalada em janeiro de 1944, a CAND respirava ideais nacionalistas com a almejada ideia de nacionalizar a fronteira e integrar a área da Colônia ao território nacional. Esses ideais consistiam em ocupar as áreas com baixa densidade demográfica por brasileiros, o que garantiria a posse da terra e o desenvolvimento regional por meio da produção de alimentos.

Criada em terras do Território Federal de Ponta Porã, a CAND teve suas terras demarcadas em duas etapas, denominadas Primeira e Segunda Zonas. Segundo Gressler e Swensson (1988, p. 82), a área total estipulada pelo governo Vargas para esse projeto de colonização foi de 300.000 ha, mas a área total demarcada foi de 267.000 ha, sendo 68.000, na Primeira Zona e 199.000, na Segunda.

A Primeira Zona foi demarcada em 1944 com 2.332 lotes rurais (68.000 ha) e 6.876 lotes urbanos (8.798 m²); já a demarcação da Segunda Zona ocorreu em 1950 com 6.500 lotes rurais (199.000 ha) e 6.832 lotes urbanos. Em 1956, as demarcações foram encerradas e a Colônia foi emancipada em 1968. Atuando em parceria com os governos federal e estadual, o projeto colonizador previa a doação, para o colono, de lote, casa, ferramentas, animais domésticos, assistência médica etc.; também era comum oferecer trabalhos na própria Colônia (Figura 3) e nas empreitas das obras do Estado, como abertura de estradas. 


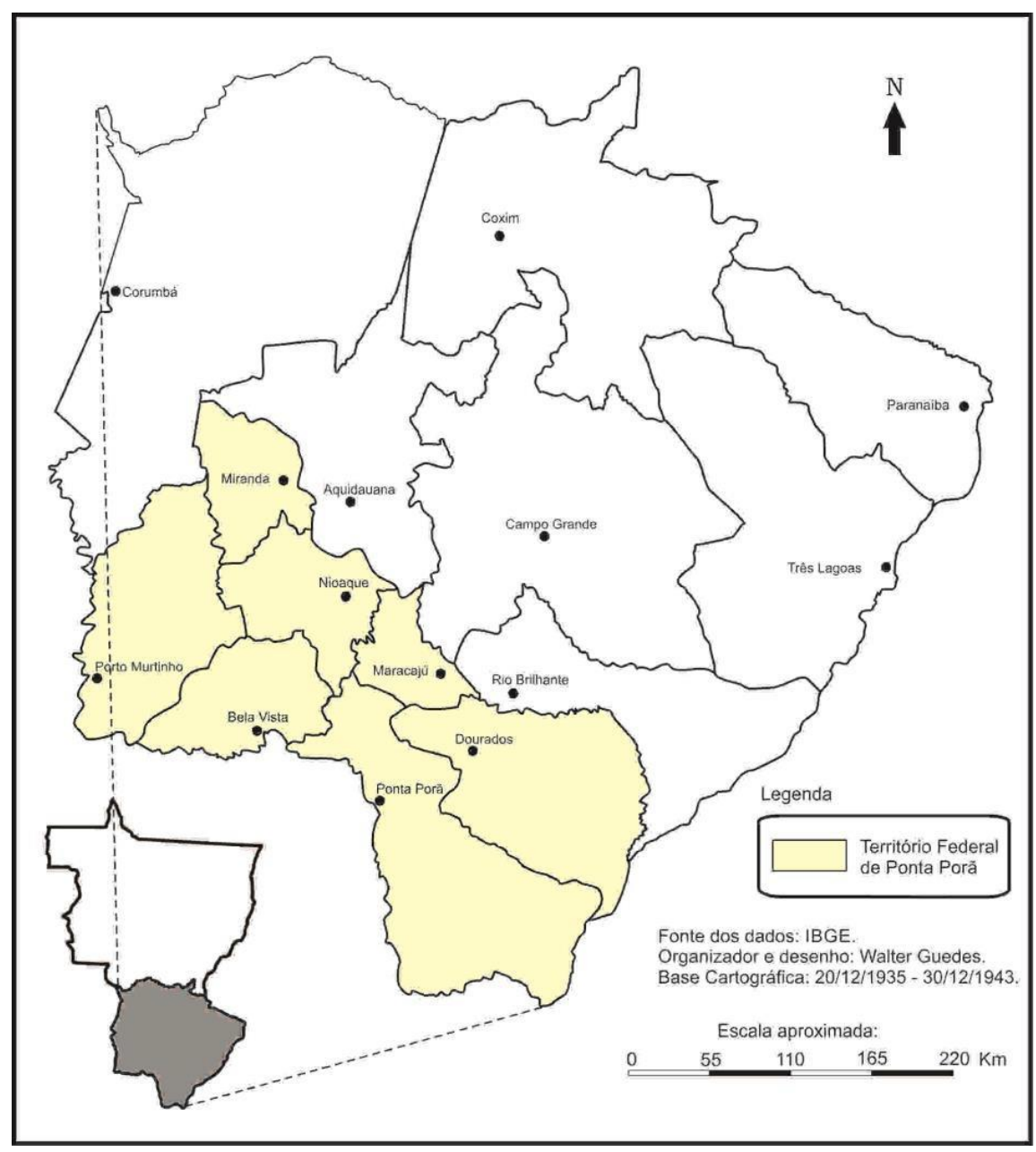

Figura 2: Área do Território Federal de Ponta Porã e ervais nativos no Sul do estado do Mato Grosso

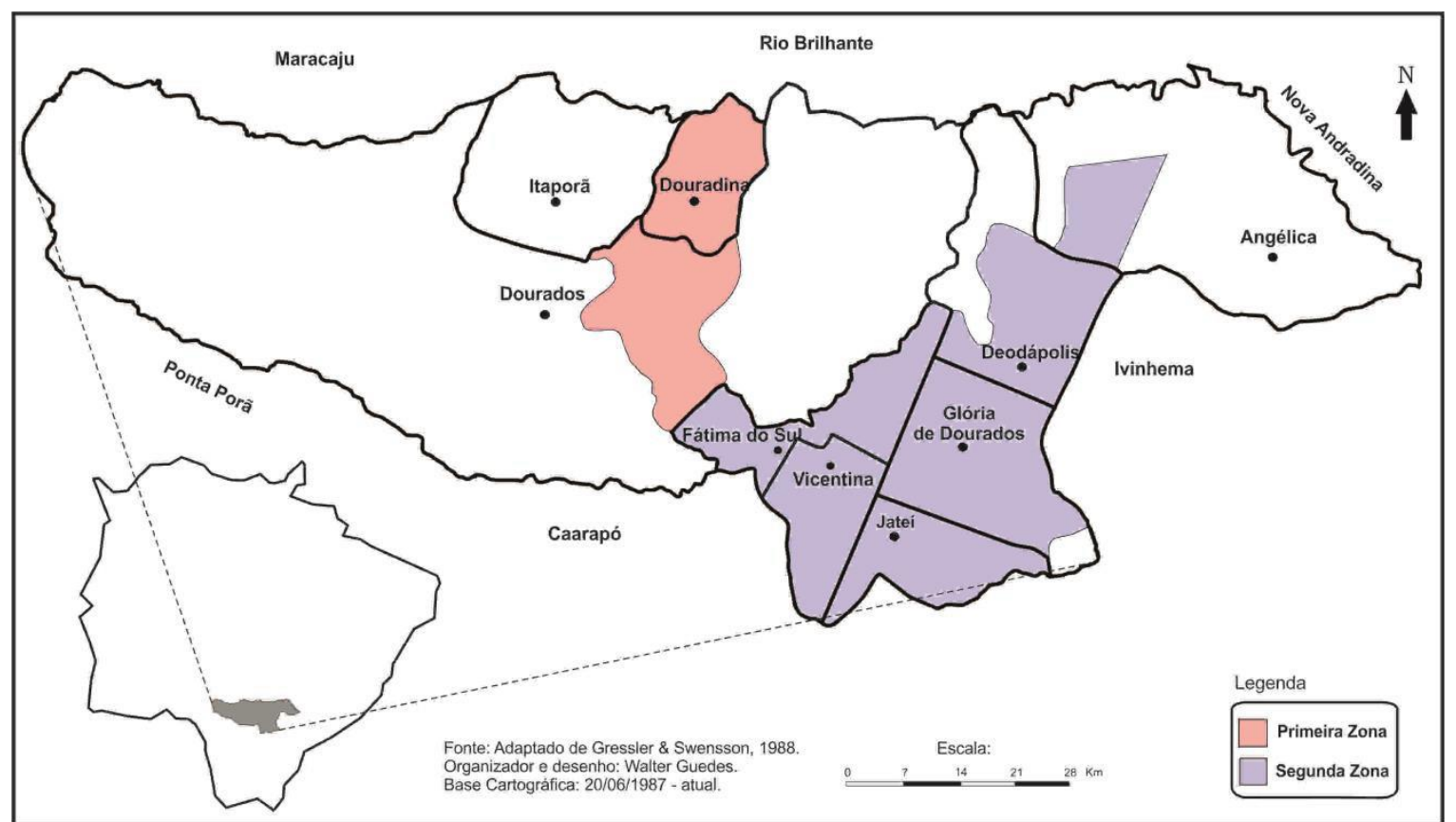

Figura 3: Localização da Colônia Agrícola Nacional de Dourados (1943-1956) 
Os benefícios do governo para o projeto de colonização não foram para todos os colonos, a Segunda Zona não foi criada nos mesmos moldes da Primeira, mas como fruto da pressão do contingente de imigrantes que lá se instalaram atraídos pelos benefícios da Primeira, ela teve que lidar com dois grandes problemas: a falta de recursos públicos e o grande contingente de imigrantes que foram atraídos pelo progresso da Primeira Zona.

A CAND foi uma excelente estratégia do governo Vargas para minimizar os problemas do desemprego nas grandes cidades, desarticular os grupos oposicionistas ao governo, ocupar e nacionalizar a fronteira com o Paraguai e fixar o homem no campo. Segundo Oliveira (1999, p. 173), a CAND também "previa a instalação de indústrias de beneficiamento dos produtos agrícolas, florestais e animais; e visava à organização de cooperativas destinadas à compra e à venda de produtos produzidos ou consumidos pelos agricultores".

Para Lenharo (1986, p. 20), a política do Estado Novo em desestruturar o poder da Cia Matte Larangeira e reestruturar o território em pequenas propriedades, abriu uma vasta frente agrícola voltada para integrar o mercado interno e para o desenvolvimento industrial. Os ideais do governo não consistiam apenas na nacionalização da fronteira, mas no avanço das relações capitalistas para essa região num processo produtivo pautado na policultura que atendesse aos interesses do setor industrial e que integrasse o mercado interno. Para Abreu (2001, p. 58): "A CAND contribuiu para a expansão da atividade agrícola do Mato Grosso, que até então era pecuarista-extrativista”.

Para receber lotes na Colônia, o interessado deveria se enquadrar em alguns critérios estabelecidos pelo governo, como ser cidadão brasileiro acima de 18 anos, ser pobre, ter aptidão para o trabalho no campo e possuir família numerosa (a preferência era para famílias com pelo menos cinco filhos). Ficavam vetados de receber lotes os funcionários públicos e aqueles que já possuíam terras. $\mathrm{O}$ estrangeiro podia receber lotes, desde que comprovasse ter bom conhecimento agrícola.

O movimento migratório de trabalhadores em busca de novas oportunidades cresceu rapidamente com a chegada de migrantes nordestinos, paulistas, paranaenses e mineiros. A produção na Colônia aumentou e se diversificou com a produção de algodão, arroz, feijão, mandioca, milho e amendoim, que abastecia o mercado local e regional. (SANTOS, 2000).

A CAND contribuiu para a expansão da atividade agrícola do Mato Grosso do Sul, garantir a ocupação territorial, "desafogar" áreas de possíveis conflitos sociais como o Nordeste, consolidar a região como celeiro produtivo regional e desenvolver e diversificar a atividade agrícola em pequenas propriedades. (ABREU, 2001).

A colonização em pequenas propriedades, pautada numa política migratória de ocupação e produção regional, foi importante para garantir a segurança na região que até então estava sob o domínio da Cia Matte Larangeira. No dizer de Oliveira e Justino (1997, p. 11): "Nessa perspectiva pequena propriedade - era então sinônimo de defesa e segurança nacional".

Os projetos de colonização, que tiveram apoio estatal, contribuíram para equipar a região da CAND com infraestrutura de estradas, escolas, rede elétrica, farmácia, dentre outros, fixando o homem no campo e estimulando a produção e o escoamento agrícola. $\mathrm{O}$ fluxo de pessoas, serviços e produtos, contribuiu, significativamente para o fomento das atividades comerciais dos centros urbanos.

Seguindo o exemplo da CAND, os governos estadual e municipal também criaram outras Colônias no Sul do Mato Grosso. Em 1946, foi criada a Colônia Municipal de Dourados (CMD) numa área de 50.000 ha, sendo elevada à categoria de município, em 1953, com o nome de Itaporã. Sobre a CMD, Carli (2008, p. 147) afirma que a sua criação possibilitou uma diversidade na produção de alimentos como abacaxi, amendoim, banana, cebola, fumo e trigo. Segundo a autora, os principais produtos produzidos na CMD, em 1954, foram: milho (7.500 ton.), mandioca (7.000 ton.), arroz (4.483 ton.), cana-de-açúcar (4.416 ton.) e feijão (1.448 ton.). 
Entre as empresas colonizadoras que atuaram no Sul do estado do Mato Grosso, é possível destacar a Companhia Vera Cruz que, em 1953, criou um grande loteamento no qual hoje é o município de Naviraí; a Colônia de Curupaí que se instalou, em 1957, no atual município de Caarapó; a Sociedade de Melhoramentos e Colonização S/A que adquiriu, em 1962, 193.000ha nos atuais municípios de Ivinhema e Glória de Dourados; a Companhia Viação São Paulo - Mato Grosso que comprou $6.000 \mathrm{~km}^{2}$ em terras dos atuais municípios de Anaurilândia, Batayporã e Bataguassu.

As colônias públicas e privadas proporcionaram uma verdadeira reconfiguração das propriedades na área de atuação da CAND ao distribuir lotes com extensão de 5 a 35 ha, nos quais hoje são os municípios de: Anaurilândia, Bataguassu, Batayporã, Caarapó, Deodápolis, Dourados, Douradina, Fátima do Sul, Glória de Dourados, Itaporã, Ivinhema, Jateí, Mundo Novo, Naviraí, Nova Andradina e Sete Quedas.

A atuação do governo Vargas, com a política de integração territorial e de industrialização, reestruturou o território regional que passou a ter, na pequena propriedade familiar, fruto de projetos de colonização, um elemento de reordenamento regional. É importante ressaltar que, diferente do extrativismo da erva-mate, que não se manteve competitivo no cenário internacional, a atividade da pecuária bovina não se desfez paralelamente às mudanças nas relações sociais que reconfiguraram tanto o território como as atividades econômicas regionais, pautadas, agora, numa política que visava anexar essa região ao circuito produtivo nacional como produtora de matéria-prima e consumidora de produtos industrializados.

Os projetos de colonização públicos ou privados, pautados na pequena propriedade rural, com uso da mão de obra familiar, foram decisivos para o processo de ocupação e inserção dessa região à economia nacional. Em 1950, já era possível vislumbrar mudanças no paradigma de produção na região da CAND, que não se configuravam majoritariamente pelas tradicionais atividades da pecuária bovina e da erva-mate, o que marcou o campo foi a diversificação das atividades agrícolas.

\section{O projeto de nacionalização da fronteira e a relação com a comunidade indígena}

Na região atingida pela CAND e por outros projetos de colonização particulares, a vinda dos imigrantes deparou-se com um agente nativo: os índios, que foram expropriados de suas terras, escravizados e mortos. A visão que o Estado tinha dos Guarani era a de que esse povo era culturalmente inferior e sua presença era considerada um obstáculo a ser superado. Para os índios restavam duas alternativas: viverem confinados em áreas nas quais o governo assim decidisse ou lutarem pela terra. Para qualquer saída o preço era alto: aculturação, discriminação, violência e miséria.

A necessidade do governo Vargas em nacionalizar a fronteira com o Paraguai expressava-se, inclusive, na preocupação que se tinha com a língua falada pelos indígenas na região - o Guarani. Para o juiz de direito e escritor Silva (2003, p. 82), o uso do Guarani dificultava o estabelecimento de um espírito nacional na fronteira - um erro imperdoável que feria a dignidade do país. Se os índios não entendiam o português, era porque, na visão do autor, não se esforçavam, pois eram sagazes e espertos.

\footnotetext{
Não aprendem a língua portuguesa, nem para isso fazem qualquer esforço. É lastimável que nós, os brasileiros, nos mostremos pouco ciosos pelo emprego regular de nossa língua em toda extensão daquelas fronteiras e em nosso trato com os paraguaios. Não vemos como justificar essa insistência de um grande número utilizando vocábulos castelhanos em um criminoso esforço para o afeamento do idioma nacional. É vulgar entre brasileiros a saudação buenos días [...], em uma ostentação singularíssima, e até ridícula.
} 
As cerimônias do povo Guarani, ricas em detalhes e simbologias, com rituais alegres, festivos, regados a danças e bebidas, incomodou autoridades regionais e membros do Estado, pois, na visão deles, a conjuntura política nacional exigia esforços de todos para a construção da nacionalidade brasileira que não coadunava com tanto desperdício de tempo em função de festas. Como relata Silva (2003, p. 82), "uma das características da raça Guarani é sua constante alegria [...], cujo sangue não experimentou uma certa reversão modificadora."

O autor busca uma explicação para aquilo que ele chama de espírito "não evoluído" do indígena, afirmando que uma possível causa da "mente infantil" dos índios poderia estar no que o autor chama de raça "cujo sangue não experimentou uma certa reversão modificadora". Silva (2003, p. 83) também afirma que tal infantilidade não é condizente "com a inteligência maliciosa do Guarani fronteiriço, em cujo seio abundam os alarifes (pessoas que agem de má fé), sendo coisa rara encontrar-se entre eles a ingenuidade do caipira, nordestino, paulista ou mineiro".

Essa cultura de festividade e de alegria era vista pelas autoridades locais, que tanto queriam difundir o espírito da nacionalidade na fronteira, como perda de tempo - ócio desnecessário. Como se não bastasse, ainda eram considerados mentirosos, que só falavam a "verdade" sob tortura. "Por mais que estejam inteirados de um fato criminoso, deles nada espera a justiça. Só a coação física poderia modificá-lo" (SILVA, 2003, p. 84). O autor ainda faz referência ao grande número de venda de instrumentos musicais para os índios em detrimento das enxadas e machados.

Seriam outras as condições da fronteira e de modo especial da baixada sulina, se machados, foices e enxadas tivessem a aceitação na razão de um décimo das sanfonas, violões, violinos e bandolins que lá se vendem. O município de Bela Vista, principal império da ociosidade, é o centro onde se podem fazer fartas observações a esse respeito. Há ali comerciantes que venderam em menos de três anos cerca de quatrocentos violões, ao passo que no mesmo espaço de tempo não conseguiram vender uma só enxada ou machado. (SILVA, 2003, p. 84).

O que as autoridades poderiam pensar da religiosidade Guarani? A resposta não poderia ser outra: uma prática profana que muito se distanciava da fé dos ditos civilizados cristãos. Os índios tinham dias santos à revelia da igreja católica; por mais que houvesse decretos que não reconheciam aquele dia como santo, para Silva (2003, p. 92), “o paraguaio não vai perder assim, à toa, um dia que já lhe deram para farras e fuzarcas". A numerosa presença de índios em velórios justificava-se, para o autor, pela festa em si, onde deixavam de trabalhar, bebiam e degeneravam a ordem local.

A ideia de confinar os índios, localizados no atual município de Dourados em reservas indígenas, remonta ao início do século 20, quando a Cia Matte Larangeira (1893-1937), que manteve o controle e domínio territorial com a exploração da erva-mate, propôs ao governo a criação de uma reserva indígena. A alternativa de confinamento foi acatada, em 1917, pelo governo, que reservou uma área no município de Ponta Porã (com o desmembramento desse município a área está hoje no município de Dourados) de 3.600 ha, sem possibilidade de ampliação, para se constituir a Reserva Indígena de Dourados (RID). Segundo Wenceslau e Silva (2011, pp. 02-03), o título definitivo da área foi emitido em 1965 como patrimônio da União, mas com 61ha a menos dos 3.600 doados, que foram incorporados às fazendas vizinhas, ficando com uma área de 3.539ha para uma população de aproximadamente 300 índios. Atualmente essa população é de aproximadamente 16.000 índios.

Nos termos da legislação vigente, no caso o art. 231 da Constituição Federal de 1988 (CASA CIVIL, 1988), a Lei 6.001/73 que dispõe sobre o Estatuto do Índio (CASA CIVIL, 1973), e o Decreto 1.775/96 que dispõe sobre o procedimento administrativo de demarcação das terras indígenas (BRASIL, 1996), as terras indígenas podem ser classificadas nas seguintes modalidades (Figura 4): 
- Terras Indígenas Tradicionalmente Ocupadas: São as terras indígenas de que trata o art. 231 da Constituição Federal de 1988, direito originário dos povos indígenas sobre as terras que tradicionalmente ocupam cujo processo de demarcação é disciplinado pelo Decreto $\mathrm{n}^{\circ}$ 1775/96;

- Reservas Indígenas: São terras doadas por terceiros, adquiridas ou desapropriadas pela União que se destinam à posse permanente dos povos indígenas. Apesar de pertencerem a União não se confundem com as terras de ocupação tradicional;

- Terras Dominiais: São as terras de propriedade das comunidades indígenas, havidas, por qualquer das formas de aquisição do domínio, nos termos da legislação civil;

- Interditadas: São áreas interditadas pela Funai para proteção dos povos e grupos indígenas isolados, com o estabelecimento de restrição de ingresso e trânsito de terceiros na área.

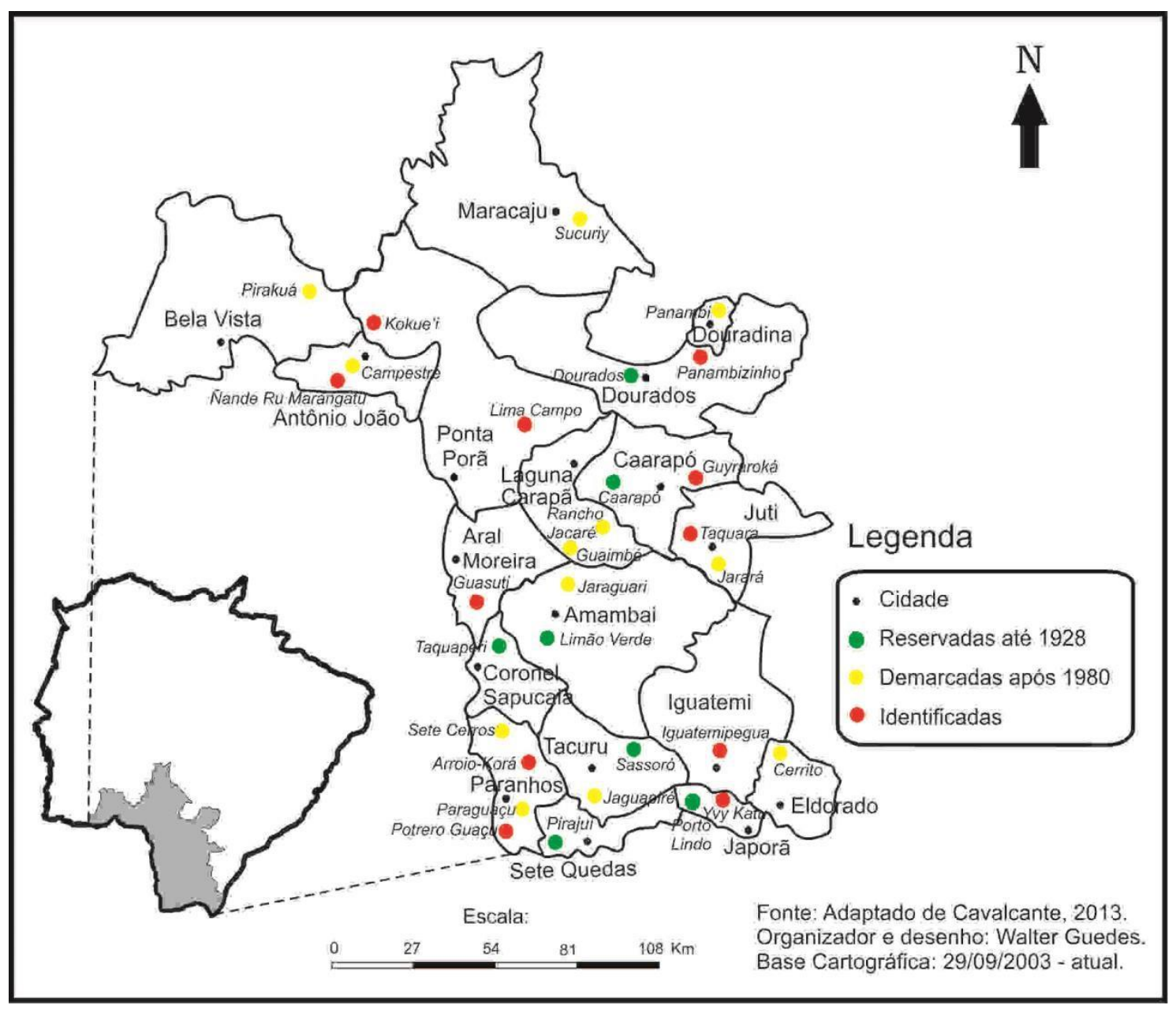

Figura 4: Áreas indígenas Guarani e Kaiowá no Sul do estado do Mato Grosso do Sul

O confinamento dos índios na RID restringiu sua área de ação aos limites da Reserva, o que comprometeu sua sobrevivência e cultura, forçando-os a se tornarem mão de obra barata para empresas e fazendeiros locais. $\mathrm{O}$ aumento da população indígena na RID não foi levado em consideração pelo governo Vargas ao incentivar o fluxo migratório e a produção regional. O próprio projeto colonizador de Vargas, que criou a Colônia de Dourados, expulsou os índios que viviam na Aldeia Panambizinho, localizada no município de Dourados, para receber colonos. 


\section{CONSIDERAÇÕES FINAIS}

A atuação do governo e da iniciativa privada, que reestruturaram o território regional em pequenas propriedades rurais com predomínio da mão de obra familiar, decorreu da necessidade de inserir essa região ao circuito produtivo nacional e de integrá-la ao mercado de produção e de consumo. Nos ideais de construir a nacionalidade brasileira, Vargas implantou uma ideologia que mobilizou muitos desempregados e trabalhadores que haviam sido expulsos do campo - foram os colonos que deram à região a "cara" do Brasil.

O deslocamento de contingentes populacionais para as regiões de baixa densidade demográfica acalmou os ânimos em torno do problema da estrutura fundiária nacional, esvaziou o discurso em torno da reforma agrária, garantiu um contingente de migrantes que foram absorvidos pelas empresas colonizadoras em terras devolutas, ampliou a produção de alimentos para o abastecimento dos centros urbanos, contribuiu para consolidar a ocupação territorial e a fronteira nacional, inseriu a região das Colônias Agrícolas ao circuito produtivo nacional como produtora de matéria-prima e consumidora de produtos industrializados e confirmou essa região como extensão do Sudeste.

\section{REFERÊNCIAS}

ABREU, S. Ocupação, racionalização e consolidação do Centro-oeste brasileiro: o espaço mato-grossense e a integração nacional. In: MARIN, J. Roberto; VASCONCELOS, C. Alves. (Orgs.). História, região e identidades. Campo Grande: UFMS, 2003, pp.263-290.

ABREU, S. Planejamento governamental: a SUDECO no espaço Mato-Grossense - contexto, propósitos e contradições. 2001. 328f. Tese (Doutorado em Geografia Humana) - Faculdade de Filosofia, Letras e Ciências Humanas, Universidade de São Paulo. São Paulo, 2001.

ARRUDA, G. Frutos da terra: os trabalhadores da Matte Larangeira. Dissertação (Mestrado em História) Instituto de Letras, História e Psicologia, Universidade Estadual de São Paulo. Assis, 233f.1989.

BRASIL. Instituto Nacional de Colonização e Reforma Agrária. Sistema Nacional de Cadastro Rural 2013. Disponível em: http://www.incra.gov.br. Acessos em: 18/10/2015.

BRASIL. Instituto Nacional de Colonização e Reforma Agrária. Decreto nº . 1.775, de 08 de janeiro de 1996. Dispõe sobre procedimentos administrativos de demarcação das terras indígenas. Brasília. Disponível em: http://www.planalto.gov.br/ccivil 03/decreto/D1775.htm. Acesso em: 23/10/2015.

CASA CIVIL. Lei $\mathrm{n}^{\circ}$. 6.001, de 19 de dezembro de 1973. Dispõe sobre o estatuto do índio. Brasília. Disponível em: http://www.planalto.gov.br/ccivil_03/Leis/L6001.htm. Acesso em: 23/10/2015.

CASA CIVIL. Senado Federal. Constituição da República Federativa do Brasil de 1988. Brasília: Senado, 2012.

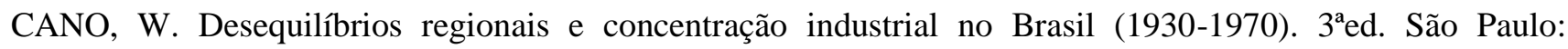
UNESP, 2007.

CANO, W. GUIMARÃES NETO, L. A questão regional no Brasil: traços gerais de sua evolução histórica. Pensamiento Iberoamericano. Madri - Instituto de Cooperation Iberoamericana, n. 10, pp. 167- 184, 1986.

CARLI, M.A.F. Dourados e a democratização da terra: Povoamento e colonização da Colônia Agrícola Municipal de Dourados (1946-1956). Dourados: UFGD, 2008, 184p.

CAVALCANTE, T.L.V. Colonialismo, território e territorialidade: a luta pela terra dos Guarani e Kaiowa em Mato Grosso do Sul. 2013. 471f. Tese (Doutorado em História) - Faculdade de Ciências e Letras de Assis Universidade Estadual Paulista. São Paulo, 2013.

CORRÊA, V.B. Coronéis e bandidos em Mato Grosso (1989-1943). 2ª ed. Campo Grande: UFMS, 2006, $231 \mathrm{p}$.

COSTA, J.C.Z. Desenvolvimento econômico e deslocamento populacional no primeiro governo Vargas (19301945). 2007. 265f. Tese (Doutorado em Geografia Humana) - Faculdade de Filosofia, Letras e Ciências Humanas, USP/São Paulo, 2007. 
FERREIRA, E. M.L; FALCÃO, M.S. Os Kaiowá e Guarani como mão de obra nos ervais da Companhia Matte Laranjeira (1890-1960). Revista de História da UEG. V. 2, n. 2, pp. 94-110, 2013.

FREITAS, W.A.; MELLO, M. A Colônia Agrícola Nacional de Goiás e a redefinição nos usos do território. Revista Sociedade e Natureza, v. 26, n. 3, pp. 471-482, 2014.

GOLDENSTEIN, L; SEABRA, M. Divisão territorial do trabalho e nova regionalização. Revista do Departamento de Geografia. n. 1, pp. 22-47, 1982. São Paulo: FFLCH/USP.

GRESSLER, L. A; SWENSSON, L.J. Aspectos históricos do povoamento e da colonização do Estado de Mato Grosso do Sul: destaque ao município de Dourados. Dourados: L. Gressler, 1988.

LENHARO, A. Colonização e trabalho no Brasil: Amazônia, Nordeste e Centro-Oeste. Campinas: Unicamp, 1986, 99p.

MACHADO, L. O. Cidades na Fronteira Internacional: Conceitos e tipologias. In: NÚÑES, Â; PADOIN, M.M.; OLIVEIRA, T.C.M. (Orgs.) Dilemas e diálogos platinos: Fronteiras. Dourados: UFGD, 2010, pp.5972.

NAGLIS, S.G.B. Marquei aquele lugar com o suor do meu rosto: os colonos da Colônia Agrícola Nacional de Dourados - CAND (1943-1960). 2007. 117f. Dissertação (Mestrado em História) - Universidade Federal da Grande Dourados. Dourados, 2007.

OLIVEIRA, B. C. A política de Colonização do Estado Novo em Mato Grosso (1937-1945). 1999. $243 f$. Dissertação (Mestrado em História) - Faculdade de Ciências e Letras, UNESP/Assis, 1999.

OLIVEIRA, B.C.; JUSTINO, V. O projeto colonizador na região da Grande Dourados: encontro e desencontros na malha fundiária. Revista de Geografia. Campo Grande - UFMS, n. 5, pp. 10-14, 1997.

SANTOS, V.D.G. A contribuição da Colônia Agrícola Nacional de Dourados (CAND) no processo de ocupação e desenvolvimento do Mato Grosso do Sul Meridional. 2000. 81p. Monografia (especialização em Geografia). Dourados: UFMS.

SILVA, J.M. Fronteiras Guaranis: a trajetória da nação cuja cultura dominou a fronteira Brasil-Paraguai. $2^{\mathrm{a}}$. ed. Campo Grande: IHGMS, 2003.

SILVA, W.G. Controle e domínio territorial no sul do estado de Mato Grosso: Uma análise de atuação da Cia Matte Larangeira no período de 1883 a 1937. Agrária. n. 15, pp. 102-125, 2011. São Paulo: FFLCH.

SKIDMORE, T. Brasil: de Getúlio a Castelo. 14ª ed. Rio de Janeiro: Paz e Terra, 2007, 512p.

VARGAS, G.D. A nova política do Brasil. Vol. III. Rio de Janeiro: José Olympio, 1941, 306p.

VARGAS, G.D. Vol. II. Rio de Janeiro: José Olympio, 1940, 200p.

VARGAS, G.D. Vol. I. Rio de Janeiro: José Olympio, 1938, 254p.

WENCESLAU, M.E; SILVA, W.G. O espaço na comunidade indígena de Dourados - identidade e auteridade. In: Anais do XIII Encuentro de Geógrafos de América Latina, 2011, Anais. Costa Rica, 2011, 12p. 